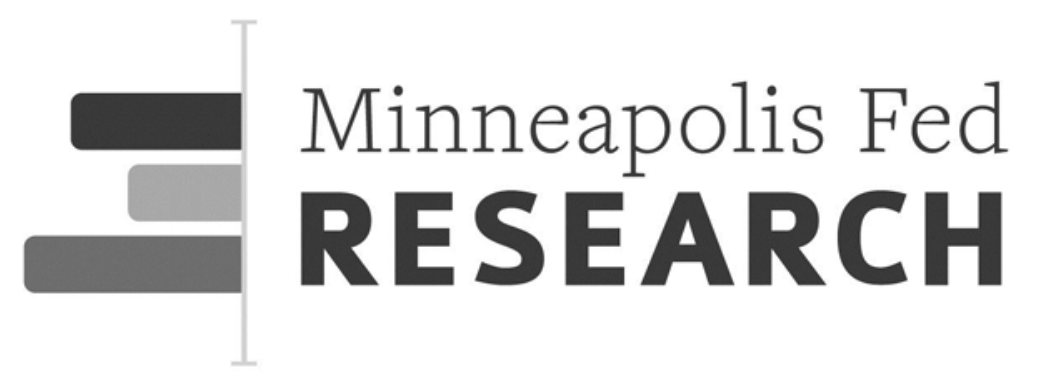

\title{
Liquidity Traps and Monetary Policy: \\ Managing a Credit Crunch \\ Online Appendix
}

\author{
Francisco Buera \\ Federal Reserve Bank of Chicago and NBER \\ Juan Pablo Nicolini \\ Federal Reserve Bank of Minneapolis and Universidad Di Tella
}

Staff Report 541

February 2017

Keywords: Liquidity trap; Credit crunch; Collateral constraints; Monetary policy, Ricardian equivalence JEL classification: E44, E52, E58, E63

The views expressed herein are those of the authors and not necessarily those of the Federal Reserve Bank of Chicago, the Federal Reserve Bank of Minneapolis, or the Federal Reserve System. 


\title{
Liquidity Traps and Monetary Policy: Managing a Credit Crunch Online Appendix
}

\author{
Francisco Buera * Juan Pablo Nicolini ${ }^{\ddagger}$
}

February, 2017

*Federal Reserve Bank of Chicago; francisco.buera@chi.frb.org.

${ }^{\dagger}$ Federal Reserve Bank of Minneapolis and Universidad Di Tella; juanpa@minneapolisfed.org.

$\ddagger$ The views expressed herein are those of the authors and not necessarily those of the Federal Reserve Bank of Chicago, the Federal Reserve Bank of Minneapolis, or the Federal Reserve System. 


\section{A Additional Proofs}

Proof of Lemma 1: First, it is useful to write explicitly the solutions for capital and the real interest rate in the steady state. If we let $\beta \equiv(1+\rho)^{-1}, \rho>0$, they are

$$
K_{s s}=\left(\frac{\alpha}{\rho+\delta}\right)^{\frac{1}{1-\alpha}}\left(\frac{1+\theta_{s s}}{2}\right)^{\frac{\alpha}{1-\alpha}}
$$

and

$$
\left(\frac{2 \theta_{s s}}{1+\theta_{s s}}\right)(\rho+\delta)=r_{s s}+\delta
$$

Now, in order to prove Lemma 1, recall equation (19) in the paper, rewritten here for convenience:

$$
1+i_{t}=\left(1+r_{t}\right) \frac{p_{t}}{p_{t-1}}
$$

Assume the lemma is true, so $i_{t}>0$ for $t \geq 2$. Using the solution for the price level from equation (19) in the paper, the solutions for the real interest rate and capital, equations (23) and (24) in the paper, and noting that $\theta_{t}=\theta^{s s}$ for $t \geq 2$, we can write it as

$$
1+i_{t}=\left[\alpha \theta_{s s}\left(\frac{1+\theta_{s s}}{2} K_{t}\right)^{\alpha-1}+(1-\delta)\right] \frac{K_{t}}{K_{t+1}}=\frac{\left[\alpha \theta_{s s}\left(\frac{1+\theta_{s s}}{2}\right)^{\alpha-1} K_{t}^{\alpha}+(1-\delta) K_{t}\right]}{\beta\left[\alpha\left(\frac{1+\theta_{s s}}{2}\right)^{\alpha} K_{t}^{\alpha}+(1-\delta) K_{t}\right]}
$$

for all $t \geq 2$. Assume now, toward a contradiction, that

$$
1+i_{t}=\frac{\left[\alpha \theta_{s s}\left(\frac{1+\theta_{s s}}{2}\right)^{\alpha-1} K_{t}^{\alpha}+(1-\delta) K_{t}\right]}{\beta\left[\alpha\left(\frac{1+\theta_{s s}}{2}\right)^{\alpha} K_{t}^{\alpha}+(1-\delta) K_{t}\right]} \leq 1
$$

Then,

$$
\alpha \theta_{s s}\left(\frac{1+\theta_{s s}}{2}\right)^{\alpha-1} K_{t}^{\alpha}+(1-\delta) K_{t} \leq \beta\left[\alpha\left(\frac{1+\theta_{s s}}{2}\right)^{\alpha} K_{t}^{\alpha}+(1-\delta) K_{t}\right],
$$

which can be written as

$$
\alpha\left(\frac{1+\theta_{s s}}{2}\right)^{\alpha} K_{t}^{\alpha}\left(\frac{2 \theta_{s s}}{1+\theta_{s s}}-\beta\right)+(1-\delta) K_{t}(1-\beta) \leq 0 .
$$


The assumption in equation (27) in the main paper implies that the first term on the left-hand side is positive. As $\delta$ and $\beta \in(0,1)$, this is a contradiction.

Proof of Lemma 2: Assume, toward a contradiction, that $i_{1}>0$. Then

$$
\bar{M}=(1-\beta) K_{1} p_{0}
$$

SO

$$
\frac{p_{1}}{p_{0}}=\frac{K_{1}}{K_{2}}
$$

and the solution for the nominal interest rate is given by

$$
1+i_{1}=\left(1+r_{1}\right) \frac{p_{1}}{p_{0}}=\left[\frac{2 \theta_{l}}{\left(1+\theta_{l}\right)}\left(\frac{1+\theta_{l}}{1+\theta_{s s}}\right)^{\alpha}(\rho+\delta)+(1-\delta)\right] \frac{K_{1}}{K_{2}},
$$

but

$$
\frac{K_{1}}{K_{2}}=\frac{\alpha\left(\frac{1+\theta_{s s}}{2}\right)^{\alpha} K_{s s}^{\alpha}+(1-\delta) K_{s s}}{\alpha\left(\frac{1+\theta_{l}}{2}\right)^{\alpha} K_{s s}^{\alpha}+(1-\delta) K_{s s}}=\frac{\alpha\left(\frac{1+\theta_{s s}}{2}\right)^{\alpha}+(1-\delta) K_{s s}^{1-\alpha}}{\alpha\left(\frac{1+\theta_{l}}{2}\right)^{\alpha}+(1-\delta) K_{s s}^{1-\alpha}} .
$$

Replacing the solution for $K_{s s}$, we obtain

$$
\frac{K_{1}}{K_{2}}=\frac{\alpha\left(\frac{1+\theta_{s s}}{2}\right)^{\alpha}+(1-\delta) \frac{\alpha}{\frac{1}{\beta}-1+\delta}\left(\frac{1+\theta_{s s}}{2}\right)^{\alpha}}{\alpha\left(\frac{1+\theta_{l}}{2}\right)^{\alpha}+(1-\delta) \frac{\alpha}{\frac{1}{\beta}-1+\delta}\left(\frac{1+\theta_{s s}}{2}\right)^{\alpha}}=\frac{1 / \beta}{\left(\frac{1+\theta_{l}}{1+\theta_{s s}}\right)^{\alpha}(\rho+\delta)+(1-\delta)}
$$

Then

$$
1+i_{1}=\frac{1}{\beta} \frac{\frac{2 \theta_{l}}{\left(1+\theta_{l}\right)}\left(\frac{1+\theta_{l}}{1+\theta_{s s}}\right)^{\alpha}(\rho+\delta)+(1-\delta)}{\left(\frac{1+\theta_{l}}{1+\theta_{s s}}\right)^{\alpha}(\rho+\delta)+(1-\delta)}
$$

We assumed the interest rate to be positive, which implies

$$
\frac{1}{\beta} \frac{\frac{2 \theta_{l}}{\left(1+\theta_{l}\right)}\left(\frac{1+\theta_{l}}{1+\theta_{s s}}\right)^{\alpha}(\rho+\delta)+(1-\delta)}{\left(\frac{1+\theta_{l}}{1+\theta_{s s}}\right)^{\alpha}(\rho+\delta)+(1-\delta)}>1
$$


which implies that

$$
\frac{2 \theta_{l}}{\left(1+\theta_{l}\right)}\left(\frac{1+\theta_{l}}{1+\theta_{s s}}\right)^{\alpha}(\rho+\delta)+(1-\delta)>\beta\left(\frac{1+\theta_{l}}{1+\theta_{s s}}\right)^{\alpha}(\rho+\delta)+\beta(1-\delta)
$$

or

$$
(1-\delta)(1-\beta)>\left(\frac{1+\theta_{l}}{1+\theta_{s s}}\right)^{\alpha}(\rho+\delta)\left[\beta-\frac{2 \theta_{l}}{\left(1+\theta_{l}\right)}\right]
$$

We now briefly characterize the right-hand side as a function of $\theta_{l}$ :

$$
f\left(\theta_{l}\right) \equiv\left(\frac{1+\theta_{l}}{1+\theta_{s s}}\right)^{\alpha}(\rho+\delta)\left[\beta-\frac{2 \theta_{l}}{\left(1+\theta_{l}\right)}\right] .
$$

Equation (27) implies that $f\left(\theta_{s s}\right)<0$, so the inequality is satisfied for $\theta_{l}$ close enough to $\theta_{s s}$, and no contradiction arises in this case.

On the other hand,

$$
f(0)=\left(\frac{1}{1+\theta_{s s}}\right)^{\alpha} \frac{(\rho+\delta)}{1+\rho} .
$$

We show now that in this case, condition (4) is violated. As $\delta>\rho$,

$$
\frac{\delta}{1-\delta}>\frac{\rho}{1+\rho}
$$

But $\theta_{s s}<1$, so

$$
\theta_{s s}<1<\frac{\delta}{1-\delta} \frac{1+\rho}{\rho}=\frac{\delta+\rho}{(1-\delta) \rho}-1,
$$

and therefore

$$
1+\theta_{s s}<\frac{\delta+\rho}{(1-\delta) \rho}
$$

As $\alpha<1$, it follows that

$$
\left(1+\theta_{s s}\right)^{\alpha}<1+\theta_{s s}<\frac{\delta+\rho}{(1-\delta) \rho},
$$


which, rearranging and dividing both sides by $1+\rho$, can be written as

$$
(1-\delta) \frac{\rho}{1+\rho}<\left(\frac{1}{1+\theta_{s s}}\right)^{\alpha} \frac{\delta+\rho}{1+\rho}
$$

But the left-hand side can be written as

$$
(1-\beta)(1-\delta)=\frac{\rho}{1+\rho}(1-\delta)<\left(\frac{1}{1+\theta_{s s}}\right)^{\alpha} \frac{\delta+\rho}{1+\rho} .
$$

Thus, by the intermediate value theorem, there exists a $\widetilde{\theta}_{l} \in\left(0, \theta_{s s}\right)$ such that

$$
(1-\delta)(1-\beta)=\left(\frac{1+\widetilde{\theta}_{l}}{1+\theta_{s s}}\right)^{\alpha}(\rho+\delta)\left[\beta-\frac{2 \widetilde{\theta}_{l}}{\left(1+\widetilde{\theta}_{l}\right)}\right] .
$$

Since $f\left(\theta_{l}\right)$ is decreasing, the zero bound will bind for all $\theta_{l} \in\left(0, \widetilde{\theta}_{l}\right]$.

\section{B The Effect of Public Debt Around $B=0$}

In this appendix we characterize the effect of public debt on GDP for two limiting cases. First, we consider the example presented in Section 3.3.2, where only entrepreneurs pay taxes and receive subsidies associated with the temporary one-period increase in government debt. For this case, we show that GDP tends to be an increasing function of the level of public debt in the neighborhood of $B=0$. Second, we consider the polar case in which only workers pay taxes and receive subsidies associated with the temporary one-period increase in government debt. In this case, we show that GDP is a decreasing function of the level of public debt in the neighborhood of $B=0$. These examples illustrate that the net effect of government debt on aggregate output depends on the particular implementation of the debt policy and on the relative size of workers and entrepreneurs in the population. 


\section{B.1 Taxing/Subsidizing Only Entrepreneurs}

Differentiating equation (25) in the paper around $B_{1}=0$,

$$
\left.\frac{\partial K_{1}}{\partial B_{1}}\right|_{B_{1}=0}=-(1-\beta)\left[1-\int \frac{\left(1+r_{s s}\right)}{R_{s s}(z)} d z\right]
$$

Similarly, differentiating equation (21) in the paper around $B_{1}=0$,

$$
\left.\frac{\partial Z_{1}}{\partial B_{1}}\right|_{B_{1}=0}=\alpha Z_{s s} K_{s s}^{-1} \frac{1-\theta}{1+\theta}
$$

Thus, the net effect on GDP around $B_{1}=0$ is as follows:

$$
\begin{array}{rlrl}
\left.\frac{\partial Y_{1}}{\partial B_{1}}\right|_{B_{1}=0} & = & \alpha Z_{s s} K_{s s}^{\alpha-1} \frac{1-\theta}{1+\theta}-\alpha Z_{s s} K_{s s}^{\alpha-1}(1-\beta)\left[1-\int \frac{\left(1+r_{s s}\right)}{R_{s s}(z)} d z\right] \\
& =\quad \alpha Z_{s s} K_{s s}^{\alpha-1}\left[\frac{1-\theta}{1+\theta}-(1-\beta)\left[1-\int \frac{\left(1+r_{s s}\right)}{R_{s s}(z)} d z\right]\right] .
\end{array}
$$

Finally, using the expressions for $R_{1}(z)$ and solving the integral, we have

$$
\left.\frac{\partial Y_{1}}{\partial B_{1}}\right|_{B_{1}=0}=\alpha Z_{s s} K_{s s}^{\alpha-1}(1-\theta)\left[\frac{1}{1+\theta}-(1-\beta)\left[1-\frac{1+r_{s s}}{r_{s s}+\delta} \theta \log \left(\frac{r_{s s}+\delta}{1+r_{s s}} \frac{1}{\theta}+1\right)\right]\right]
$$

where around $B_{1}=0$ the real interest rate $r_{s s}=(\rho+\delta) 2 \theta /(1+\theta)-\delta$. It is straightforward to show that this expression is positive for $\beta$ close to 1 or $\theta$ close to 0 .

\section{B.2 Taxing/Subsidizing Only Workers}

In this case,

$$
\left.\frac{\partial K_{1}}{\partial B_{1}}\right|_{B_{1}=0}=-1
$$

and the effect on TFP is also given by (6). Thus,

$$
\left.\frac{\partial Y_{1}}{\partial B_{1}}\right|_{B_{1}=0}=-\alpha Z_{s s} K_{s s}^{\alpha-1} \frac{2 \theta}{1+\theta}<0
$$




\section{Distribution of Welfare Impacts}

In the previous section, we focused on the impact of policies on aggregate outcomes and factor prices. The aggregate figures suggest a relatively simple trade-off at the aggregate level. These dynamics, though, hide very disparate effects of a credit crunch and alternative policies among different agents. Although workers are hurt by the drop in wages, the profitability of active entrepreneurs and their welfare can increase as a result of lower factor prices. Similarly, unproductive entrepreneurs are bondholders in equilibrium, and therefore their welfare depends on the behavior of the real interest rate.

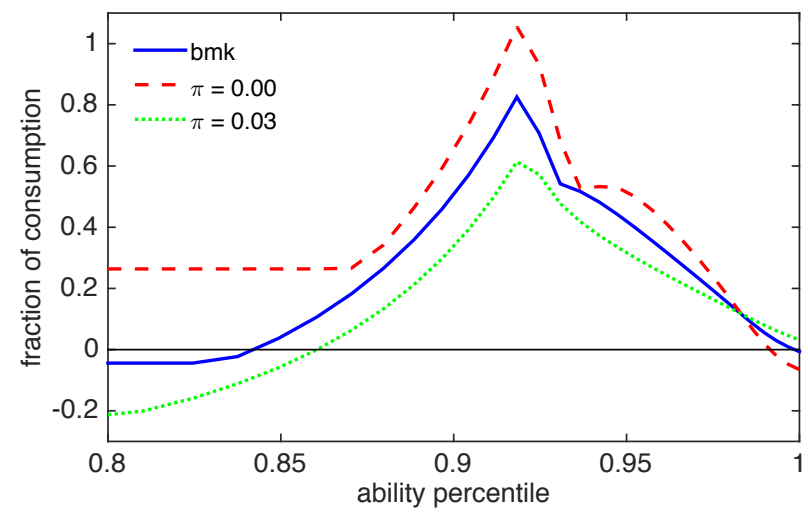

Figure A1: Distribution of welfare gains among entrepreneurs. The solid line corresponds to the benchmark case shown in Figure 3 in the main paper. The dashed and dotted lines are for the cases with alternative inflation targets, $\pi=0.00$ and $\pi=0.03$, reported in Figure 7 in the main paper. The welfare gains for workers are $-0.03,-0.05$, and -0.02 , and in the benchmark, $\pi=0.00$ and $\pi=0.03$, respectively.

Figure $\mathrm{C}$ presents the impact of a credit crunch on the welfare of workers and entrepreneurs of different abilities under alternative inflation targets for the bailout case. We measure the welfare impact of a credit crunch in terms of the fraction of consumption that an individual is willing to permanently forgo in order to experience a credit crunch. ${ }^{1}$ If positive (negative), we refer to this measure as the welfare gains (losses) from a credit crunch and alternative policy responses.

The dotted line shows the welfare gains for entrepreneurs from a policy that implements a $3 \%$ inflation rate as a function of the percentile of their ability distribution.

\footnotetext{
${ }^{1}$ For entrepreneurs, we consider the welfare of individuals that at the time of the shock have wealth equal to the average wealth of their type. For workers, their welfare is calculated assuming, as is true in the steady state of the model, that they own no wealth when the credit crunch is announced.
} 
This level of inflation is implemented with a negligible increase in the net supply of outside liquidity, and therefore, the economy in the long run returns to the initial steady state. Unproductive entrepreneurs are clearly hurt by a credit crunch, since the return on the bonds they hold becomes negative for over 31 quarters and only gradually returns to the original steady state. Their losses amount to over $20 \%$ of permanent consumption. On the contrary, entrepreneurs who become active as the credit crunch lowers factor prices, and who increase their profitability, benefit the most. The same effect increases welfare for previously active entrepreneurs, but they are hurt by the tightening of collateral constraints, which limit their ability to leverage their high productivity. Clearly, workers are hurt by experiencing a credit crunch, since the wages drop for a number of periods. The credit crunch amounts to a permanent drop of 2 percentage points in their consumption.

The other two curves in Figure $\mathrm{C}$ show the welfare consequences of lower inflation targets. The solid line corresponds to the benchmark economy, where the inflation is closed to $2 \%$, and the dashed line is an economy with no inflation. The lower the inflation target, the higher the real interest rate, both during the credit crunch and in the new steady state. ${ }^{2}$ Unproductive entrepreneurs benefit from the highest interest rate. Similarly, productive entrepreneurs benefit from the lowest wages associated with the lowest capital during the transition and in the new steady state. ${ }^{3}$ Although individual entrepreneurs do not internalize it, collectively they benefit from the lower wages associated with a lower aggregate stock of capital. The lower the inflation target, the lower the capital stock and the lower the wages, so the welfare of workers goes down when the target goes down.

\footnotetext{
${ }^{2}$ The government debt in the new steady state will be higher the lower the inflation target is. In the model, a higher level of government debt implies a lower level of capital in the new steady state.

${ }^{3}$ The nonmonotonic nature of the welfare effects is related to the heterogeneous impact due to the changing nature of the occupational choice of agents during the transition. For example, the entrepreneur that benefits the most is the most productive inactive entrepreneur in the steady state. As the real rate goes down, that agent becomes an entrepreneur and starts borrowing to profit from the difference between his productivity and the now low interest rate and also from the lower equilibrium wage. On the other hand, the most productive entrepreneur also benefits from the low input prices but is hurt by the reduction in her ability to borrow. Thus, although she gets a higher margin per unit of capital, she can only manage a lower amount of capital.
} 


\section{Environment with Sticky Wages}

In this appendix we describe the extension with rigid wages that is solved in Section 4.3.1 in the main paper and in Appendix E.2. In order to allow for sticky wages, we now consider the case in which workers are grouped into households with a continuum of members indexed by $h \in[0,1]$, each supplying a differentiated labor input $l_{h t}$. Each member is endowed with a unit of time. Preferences of the household are described by

$$
\sum_{t=0}^{\infty} \beta^{t}\left[\zeta \nu \log c_{1 t}^{W}+\zeta(1-\nu) \log c_{2 t}^{W}+(1-\zeta) \log \left(N_{t}\right)\right]
$$

where leisure is

$$
N_{t}=1-\int_{0}^{1} l_{h t} d h
$$

The differentiated labor varieties aggregate up to the labor input $L_{t}$, used in production by individual entrepreneurs, according to the Dixit-Stiglitz aggregator

$$
L_{t}=\left[\int_{0}^{1} l_{h t}^{\frac{\eta-1}{\eta}} d h\right]^{\frac{\eta}{\eta-1}}, \eta>1
$$

Each member of the household, which supplies a differentiated labor variety, behaves as though under monopolistic competition. They set wages as in Calvo (1983), with the probability of being able to revise the wage at $1-\alpha^{w}$. This lottery is also i.i.d. across workers and over time. The workers that are not able to set wages in period 0 all share the same wage $w_{-1}$. Other prices are taken as given.

There is a representative firm that produces homogeneous labor to be used in production by the entrepreneurs using the production function (9). The representative

firm minimizes $\int_{0}^{1} w_{h t} l_{h t} d h$, where $w_{h t}$ is the wage of the $h$-labor, for a given aggregate $L_{t}$, subject to (9). The demand for $n_{h t}$ is

$$
l_{h t}=\left(\frac{w_{h t}}{w_{t}}\right)^{-\eta} L_{t}
$$

where $W_{t}$ is the aggregate wage level, given by

$$
w_{t}=\left[\int_{0}^{1} w_{h t}^{1-\eta} d h\right]^{\frac{1}{1-\eta}}
$$


It follows that $\int_{0}^{1} w_{h t} n_{h t} d h=w_{t} L_{t}$. In order to simplify the analysis, we also assume that workers are hand to mouth. In this case, the representative worker maximizes

$$
E_{0} \sum_{t=0}^{\infty} \beta^{t}\left[\zeta \nu \log c_{1 t}^{W}+\zeta(1-\nu) \log c_{2 t}^{W}+(1-\zeta) \log \left(N_{t}\right)\right]
$$

subject to

$$
\begin{aligned}
& c_{1 t}^{W}+c_{2 t}^{W}+\frac{m_{t+1}^{W}}{p_{t}}=\frac{1}{p_{t}} \int_{0}^{1} w_{h t} l_{h t} d h+\frac{m_{t}^{W}}{p_{t}}-T_{t}^{W}, \\
& l_{h t}=\left(\frac{w_{h t}}{w_{t}}\right)^{-\eta} L_{t},
\end{aligned}
$$

and

$$
c_{1 t}^{W} \leq \frac{m_{t}^{W}}{p_{t}} .
$$

Note that although consumption and total labor will not be stochastic, each particular $w_{h t}$ will be a random variable. From the first-order conditions of representative workers, we obtain

$$
w_{h t}=\tilde{w}_{t}=\frac{\eta}{\eta-1} \sum_{j=0}^{\infty} \xi_{t+j} \frac{1-\zeta}{\zeta(1-\nu)} \frac{p_{t+j} c_{2 t+j}^{W}}{N_{t+j}}
$$

where

$$
\xi_{t+j}=\frac{\left(\beta \alpha^{w}\right)^{j} \frac{\zeta(1-\nu)}{c_{2 t+j}^{W}} \frac{1}{p_{t+j}} w_{t+j}^{\eta} L_{t+j}}{\sum_{j=0}^{\infty}\left(\alpha^{w} \beta\right)^{j} \frac{\zeta(1-\nu)}{c_{2 t+j}^{W}} \frac{1}{p_{t+j}} w_{t+j}^{\eta} L_{t+j}}
$$

and

$$
\sum_{j=0}^{\infty} \xi_{t+j}=1
$$

The evolution of the cost of a composite unit of labor is

$$
w_{t}=\left[\left(1-\alpha^{w}\right) \tilde{w}_{t}^{1-\theta^{w}}+\alpha^{w} w_{t-1}^{1-\theta^{w}}\right]^{\frac{1}{1-\theta^{w}}}
$$


and

$$
L_{t}=\left[\alpha^{w}\left(\frac{w_{t-1}}{w_{t}}\right)^{-\theta^{w}} \frac{1-N_{t-1}}{L_{t-1}}+\left(1-\alpha^{w}\right)\left(\frac{\tilde{w}_{t}}{w_{t}}\right)^{-\theta^{w}}\right]^{-1}\left(1-N_{t}\right)
$$

solves for the aggregate composite labor input given aggregate leisure.

To implement this extension, we follow Correia et al. (2013) and calibrate $\zeta=0.3$, $\eta=3$, and $\alpha^{w}=0.85$. To simplify the calculations, we consider the cashless limit. The other parameter values are set as in the other numerical examples.

\section{E Sensitivity and Robustness}

We present two sensitivity and robustness analyses of our benchmark results presented in Section 4.2 of the main paper. First, we consider simulations under alternative calibrations of the collateral constraint in the initial stationary equilibrium, $\theta_{0} \in\{0.59,0.79\}$, and discuss other possible extensions of the model to capture the importance of unconstrained firms in the US economy. Secondly, we consider simulations for the extension of the benchmark model with sticky wages and endogenous labor supply introduced in Section D of this online appendix. Thirdly, we present long-run forecasts for GDP, TFP, and the capital stock under alternative assumptions about the evolution of collateral constraints beyond the sample period in which we calibrate the evolution of the collateral constraint to match the observed path of the real interest rate. Finally, we present simulations under alternative measures of the increase in the supply of government liabilities.

\section{E.1 Alternative Values of $\theta_{0}$}

We calibrate the initial parameter of the collateral constraint, $\theta_{0}=0.69$, to match the average ratio of liabilities to nonfinancial assets for the US nonfinancial business sector between 1997:Q3 and 2007:Q3. On the one hand, we could argue for a smaller number given that liabilities are financing nontangible assets. On the other hand, we could argue for a larger number if we interpret that debt in the model proxies for other sources of external finance, such as equity issuance by public firms. We now present results for two alternative calibrations.

In particular, we consider a calibration with initially tighter and looser collateral 
constraints, $\theta_{0} \in\{0.59,0.79\}$. To match the interest rate and debt to GDP ratio in the initial steady state, we recalibrate the discount factor and the initial level of debt (and taxes). ${ }^{4}$ As before, we choose the evolution of the collateral constraint $\theta_{t}$ and the debt label to match the dynamics of the real interest rate and the debt to GDP ratio during the Great Recession.
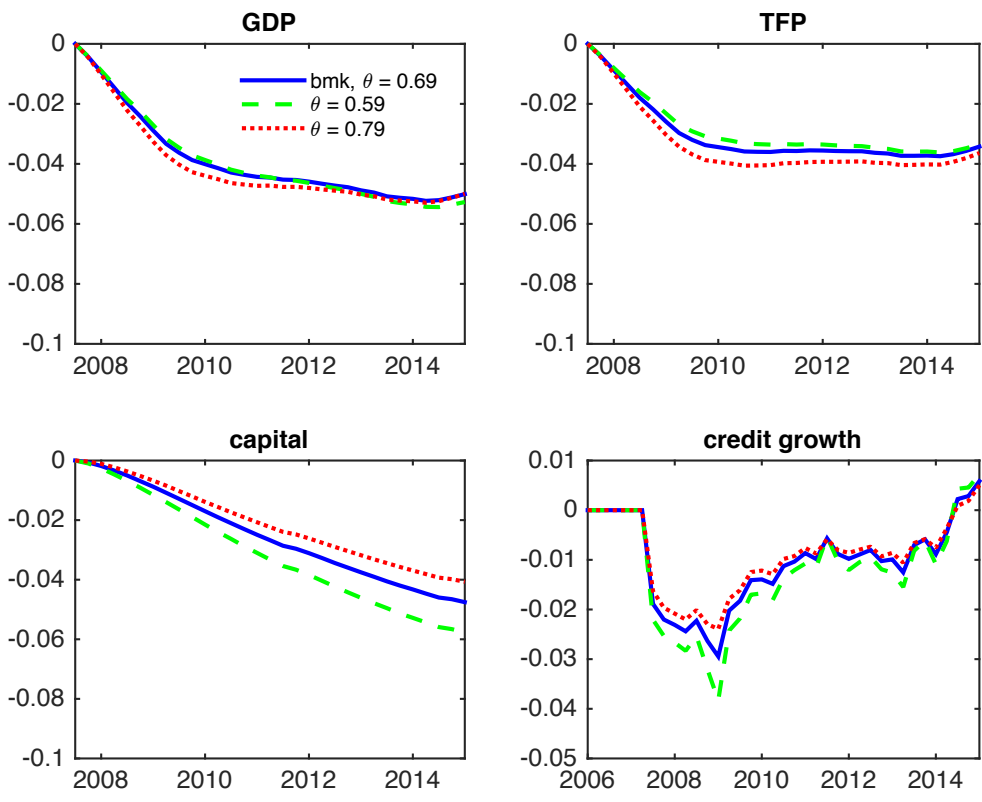

Figure A2: Simulations with alternative values of $\theta_{0}$. The solid line correspond to $\theta_{0}=0.69$, the benchmark case shown in Figure 3 of the main paper. The dashed and dotted lines correspond to calibrations using lower and higher initial values for the collateral constraint, $\theta_{0}=0.59$ and $\theta_{0}=0.79$.

The results for the alternative calibration are in Figure A2. The dynamics of GDP (top left panel) are mostly unchanged across alternative calibrations. The calibration with an initially looser constraint is associated with a deeper drop in TFP (top right panel) but a less pronounced drop in capital accumulation (bottom left panel). At the same time, the calibration with an initially looser constraint requires a smaller percentage drop in the collateral constraint to match the drop in the real interest rate. This, together with the smaller drop in aggregate capital, explains the smaller drop in the growth rate of credit (bottom right panel).

An alternative approach to evaluate the robustness of the results to the tightness of

\footnotetext{
${ }^{4}$ The value of the discount factor equals 0.9826 and 9898 in the low and high $\theta$ calibrations, respectively.
} 
the constraints would be to consider extensions of the model with unconstrained, active entrepreneurs. ${ }^{5}$ There are two natural ways to extend the model to have unconstrained, active entrepreneurs.

One alternative is to assume diminishing returns at the individual level and introduce idiosyncratic productivity shocks (Buera et al., 2015). In this case, entrepreneurs who remain productive for a long enough time would accumulate enough net worth to run their business at the unconstrained (finite) scale and save some of their net worth in bonds. An inconvenient feature of this alternative is that we would lose the tractability that allows us to illustrate the model mechanisms.

A more tractable alternative is to assume that there is an exogenous subset of the economy that is unconstrained, and this subsector is modeled as a representative firm operating a Cobb-Douglas production function. This sector is often refered to as the corporate sector, in juxtaposition to the constrained, entrepreneurial sector (see Bassetto et al., 2015). We conjecture that in this case, the calibration would require a larger drop in the collateral constraint for the entrepreneurial sector but a relatively similar decline in the growth rate of overall credit, since some of the credit and resources would be reallocated from the entrepreneurial sector to the corporate sector. This reallocation is conceptually similar to the reallocation captured in our model between the active, constrained entrepreneurs and the inactive, unconstrained entrepreneurs.

\section{E.2 Benchmark Simulations with Sticky Wages and Endoge- nous Labor Supply}

As we show in Section 4.2 of the main paper, the Great Recession is characterized by a particularly large drop in labor input. Here we explore the extent to which this drop can be captured by the extension with sticky wages and endogenous labor supply introduced in Section D. As before, we choose the evolution of the collateral constraint $\theta_{t}$ and the debt level to match the dynamics of the real interest rate and the debt to GDP ratio during the Great Recession.

The results for this extension are shown in Figure A3. This extension is able to capture qualitatively, but certainly not quantitatively, the persistent drop in employment (top right panel). The endogenous response of employment results in a marginally

\footnotetext{
${ }^{5}$ In our model, all active entrepreneurs (i.e., those with $z \geq \hat{z}$ ) are constrained, whereas all inactive entrepreneurs (i.e., those with $z<\hat{z}$ ) are unconstrained.
} 

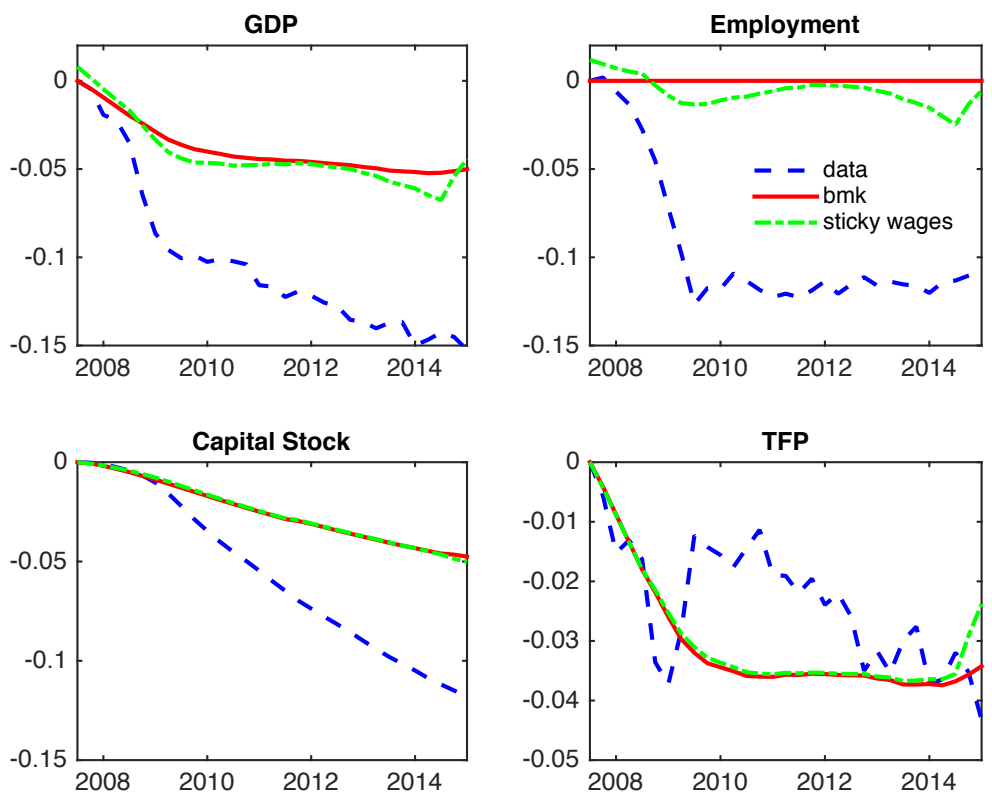

Figure A3: Benchmark simulations with sticky wages and endogenous labor supply. The dashed and solid lines reproduce the data and benchmark simulations shown in Figure 3 of the main paper. The dotted-dashed line corresponds to a variation of the benchmark simulations using a model with sticky wages.

larger contraction in GDP (top left panel), but it does not have a visible affect on capital accumulation or TFP (bottom two panels).

\section{E.3 Long-run Forecasts}

In this section we present long-run forecasts for GDP, TFP, and the capital stock under alternative assumptions about the evolution of the collateral constraints beyond the sample period in which we calibrate the evolution of the collateral constraint to match the observed path of the real interest rate. Beyond the sample period, we assume that the collateral constraint mean-reverts according to the simple recursion $\lambda_{t} \equiv 1 /\left(1-\theta_{t}\right)=\rho \lambda_{t-1}+(1-\rho) \lambda_{2007 Q 3}$, for $t \geq 2015 Q 2$.

In Figure A4 we present two alternative forecasts. The solid line corresponds to the evolution of the economy for the case $\rho=0.95$. This is the assumption we make in our benchmark exercise. The dashed line corresponds to the case in which the collateral constraint remains fixed at the last calibrated value (i.e., $\rho=1$ ). Naturally, in this second case the economy remains stagnant. 

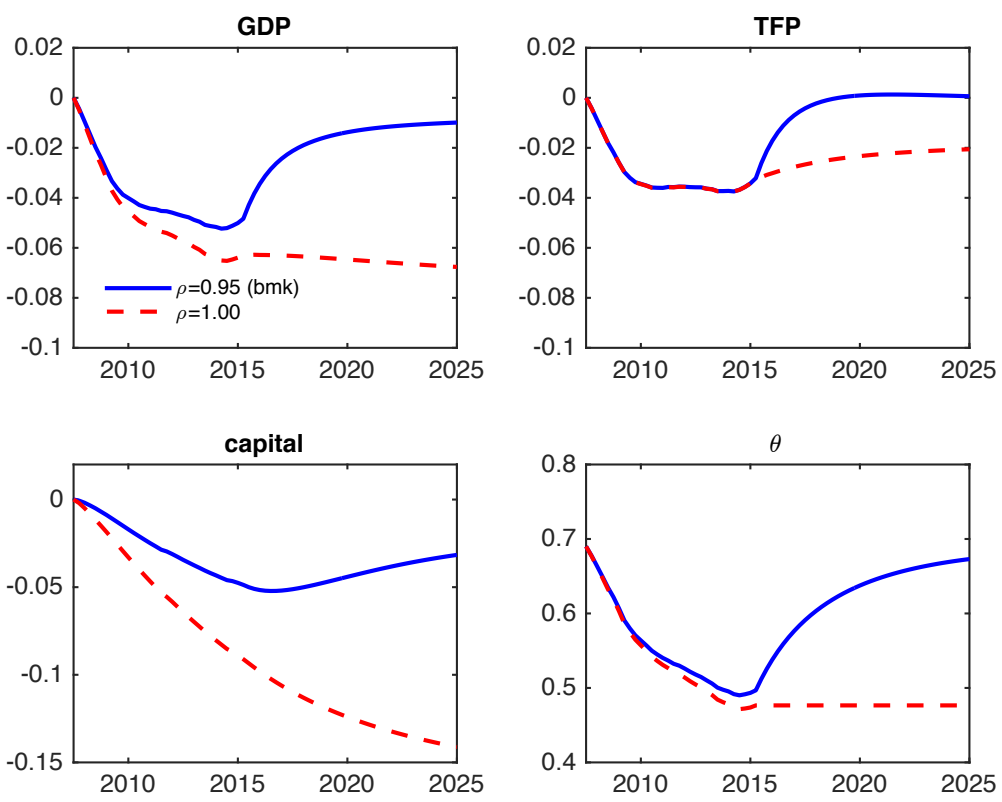

Figure A4: Long-run forecasts under alternative paths for the collateral constraint, $\lambda_{t} \equiv 1 /\left(1-\theta_{t}\right)=\rho \lambda_{t-1}+(1-\rho) \lambda_{2007 Q 3}$, for $t \geq 2015 Q 2$. The solid line corresponds to the evolution of the economy under the assumption that corresponds to $\rho=0.95$. This is the assumption we make in our benchmark exercise. The dashed line gives the case in which the collateral constraint remains fixed at the last calibrated value (i.e., $\rho=1)$.

\section{E.4 Alternative Definition of Government Liabilities}

In the final sensitivity analysis, we consider an alternative definition of government liabilities. In our benchmark calibration, we assume that the total liabilities of the government equal the sum of the total public federal debt and the Federal Reserve Banks' balance sheet net of their holdings of Treasury bonds. Here we consider a narrower notion, which nets out the liabilities of the Fed that are backed by the holding of mortgage-backed securities. In this narrower definition, the total government liabilities equal the total public federal debt.

In Figure A5 we present the evolution of GDP, TFP, capital, and the government debt to GDP ratio under the alternative notions of the total supply of government liabilities. The effect on the aggregate variables is negligible. 

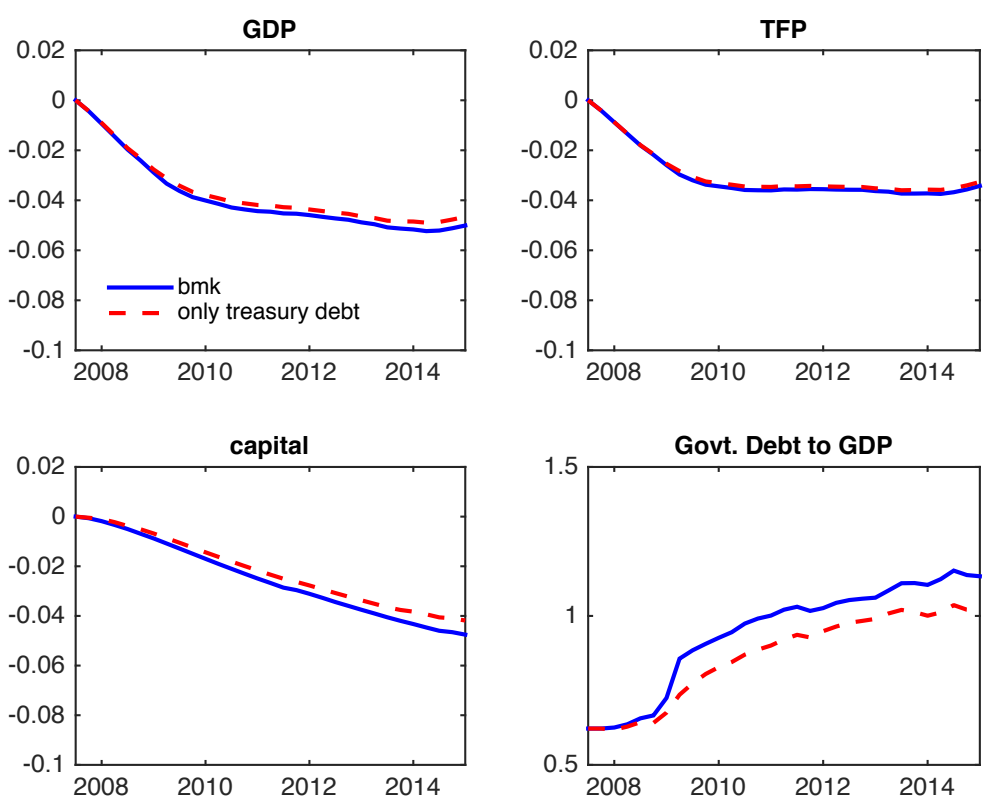

Figure A5: Benchmark simulations using alternative definitions of government liabilities. The solid line reproduces the benchmark simulations from Figure 3 in the main paper. In this case, government debt includes the total public federal debt plus the Federal Reserve Banks' balance sheet net of their holding of Treasury bonds. The dashed line corresponds to the simulations when government liabilities only include the total public federal debt.

\section{F Monetary or Fiscal Policy?}

At the zero bound, real money and bonds are perfect substitutes. Thus, standard open market operations in which the central bank exchanges money for short-term bonds have no impact on the economy. What is needed is an effective increase in the supply of government liabilities, which at the zero bound can be money or bonds. How can these policies be executed? Clearly, one way to do it is through bonds, taxes, and transfers. But another way is through a process described long ago: helicopter drops, whereby increases of money are directly transferred to agents. Sure enough, to satisfy the government budget constraint, these helicopter drops need to be compensated with future "vacuums" (negative helicopter drops).

Although the distinction between a central bank or the Treasury making direct transfers to agents may be of varying relevance in different countries because of alternative legal constraints, there is little conceptual difference in the theory. To fully control inflation during a severe credit crunch, the sum of real money plus bonds must 
go up at the zero bound. Otherwise, there will be an initial deflation, followed by an inflation rate that will be determined by the negative of the real interest rate. If these policies are understood as being outside the realm of central banks, then central banks should not be given tight inflation target mandates: inflation is out of their control during a severe credit crunch.

\section{G Construction of the Data}

In this appendix we describe how we compute the quarterly series for output, hours, capital stock, and total factor productivity.

\section{G.1 Output, $Y_{t}$}

We use the quarterly series of Real Gross Domestic Product (NIPA 1.1.6) in the period 1947:Q1 to 2016:Q2.

\section{G.2 Total Hours, $L_{t}$}

We updated the series in Cociuba et al. (2012), available online at https://sites.google.com/site/simonacociuba/research.

\section{G.3 Capital, $K_{t}$}

We used the perpetual inventory method in order to compute the capital stock series.

Real investment, $I_{t}$ : We added the series of Nominal Private Investment (NIPA Table 5.1) to Nominal Government Investment (NIPA Table 5.1) in order to have a series of Nominal Investment. We then divided the series of Nominal Investment by the Deflator of the Gross Domestic Product (GDP) series in order to compute the series for Real Investment, $I_{t}$. The GDP Deflator was computed as Nominal GDP (NIPA Table 1.1.5) divided by Real GDP (NIPA Table 1.1.6).

Depreciation series, $\left(\delta K_{t} / Y_{t}\right)_{\text {data }}$ : We divide the series of Consumption of Fixed Capital (NIPA Table 5.1) by Nominal GDP (NIPA Table 1.1.5) in order to compute a series of capital depreciation over GDP, $\left(\delta K_{t} / Y_{t}\right)_{d a t a}$. 
Capital stock, $K_{t}$, and depreciation rate, $\delta$ : We need to set values for $K_{0}$ and $\delta$. Once we have both, the series of capital stock is constructed according to $K_{t+1}=$ $I_{t}+(1-\delta) K_{t}$. We choose $K_{0}$ and $\delta$ by solving the following fixed point problem:

1. The average depreciation of the constructed series $\left(\delta K_{t} / Y_{t}\right)_{\text {constructed }}$ matches the average depreciation in the data $\left(\delta K_{t} / Y_{t}\right)_{d a t a}$.

2. The initial capital stock to output ratio of the constructed series in $1947, K_{1947} / Y_{1947}$, matches the average capital stock to output ratio of the constructed series in the period 1947:Q1 to 1951:Q4.

We have $K_{0}=16525$, which represents a capital-output ratio of 8.5 in 1947:Q1. Note that this ratio is computed for quarterly GDP. If we multiply Real GDP in 1947:Q1 by 4, which represents annual GDP in 1947:Q1, the ratio would be 2.1. Regarding the depreciation rate, $\delta$, we have a quarterly depreciation rate of $1.41 \%$, which is equivalent to an annual depreciation rate of $5.52 \%$.

\section{G.4 Total Factor Productivity, $A_{t}$}

We assume a Cobb-Douglas aggregate production function: $Y_{t}=A_{t} K_{t}^{\alpha} L_{t}^{1-\alpha}$. We have computed $Y_{t}, K_{t}$, and $L_{t}$. We set $\alpha=0.3618$ and compute total factor productivity as

$$
A_{t}=\frac{Y_{t}}{K_{t}^{\alpha} L_{t}^{1-\alpha}} .
$$

\section{H The Behavior of Capacity Utilization Adjusted TFP}

In this appendix, we compare the behavior of total factor productivity computed with a series of capital that has been adjusted by capacity utilization, as computed by Fernald (2012). We compare the behavior of that series with the one used in the main text. As we show, the results that are relevant for the analysis in the main paper are essentially the same for both series.

We apply to the new series the same procedures we applied to all the series that exhibit trend in the main paper. First, we compute linear trends to the logarithm of the series for three subperiods, all ending in quarter III of 2007, and starting in 
1947:Q3, 1960:Q1 and 1980:Q1. Table A.1 (equivalent to Table 2 in the main paper) depicts the results for the two TFP series.

\begin{tabular}{clll} 
& \multicolumn{3}{c}{ Initial Period } \\
\cline { 2 - 4 } & $1947: \mathrm{Q3}$ & $1960: \mathrm{Q} 1$ & $1980: \mathrm{Q} 1$ \\
\hline Our TFP & 0.027 & 0.023 & 0.028 \\
Adj TFP & 0.030 & 0.025 & 0.025 \\
\hline
\end{tabular}

Table A1: Average quarterly growth of (log) TFP from the specified dates and 2007:Q3.

As can be seen, for the adjusted TFP, the trend is the same in the last two subperiods. Note also that the estimated trend is lower for the adjusted TFP.

The second step is to compute, for the period 2007:Q3 until 2015:Q1, the difference between the value for TFP and its trend, computed for the last period, for both TFP series, both normalized to be zero for the first period of the sample (equivalent to the values reported in Figure 3 in the main paper). Figure A6 depicts both series.

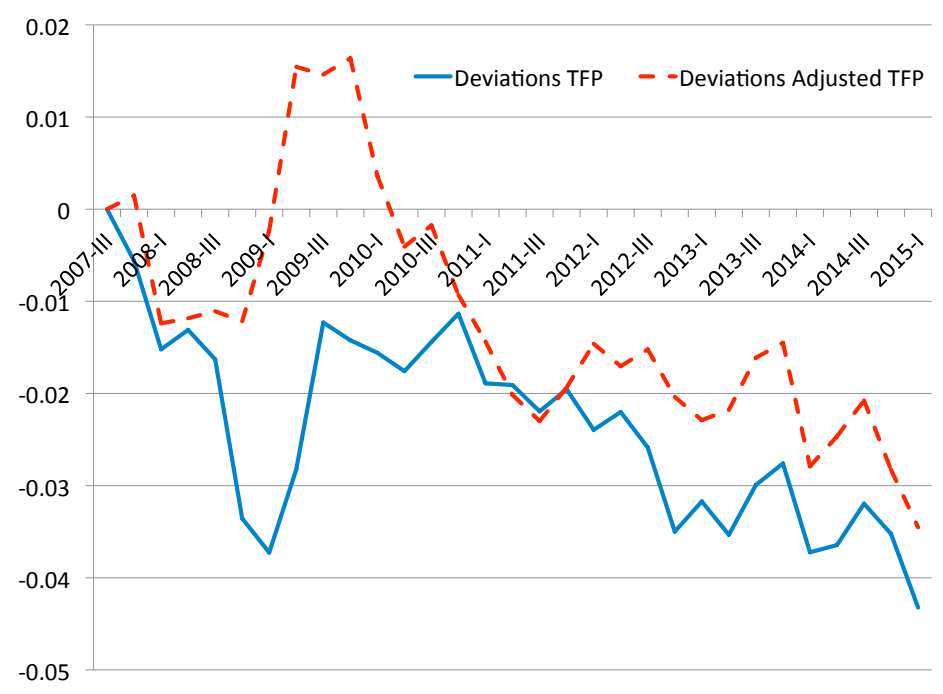

Figure A6: Comparing the evolution of detrended TFP and utilization-adjusted TFP, 2007:Q3 to 2015:Q1.

As can be seen, despite significant differences at business cycle frequencies (which we ignore in the paper), the behavior of both measures is similar: the overall drop for our measure is $4.3 \%$, whereas the drop for the adjusted TFP is $3.5 \%$.

The reason for the milder drop in the adjusted measure is purely driven by the lower trend estimated for the adjusted measure. As it turns out, the difference between the 
two measures of TFP in 2007:Q3 (equal to 6.75\% in favor of the adjusted measure) is essentially the same at the end of our sample, 2015:Q1 (equal to 6.73\%). Thus, leaving aside the differences at very high frequencies, the long-run behavior of both series is very similar.

One important difference between the two series though, can be appreciated with a picture that resembles Figure 2 in the main paper. In that figure, we reported the deviations from trend (using the estimates obtained for the sample that starts in 1980:Q1) for the whole period 1980:Q1 to 2015:Q1. Figure A7 contains those deviations for the two measures of TFP.

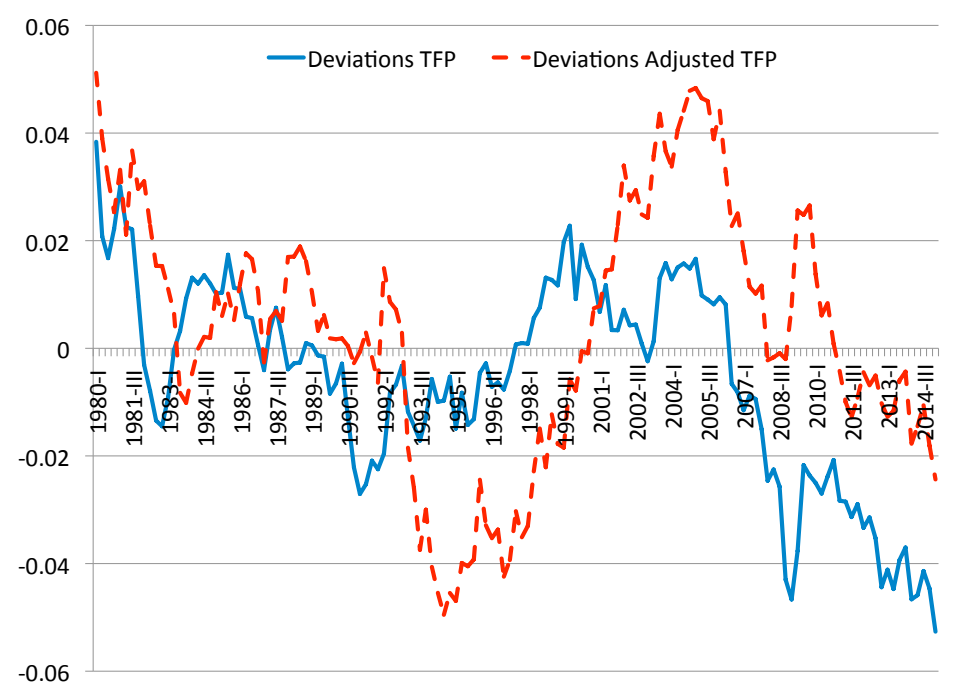

Figure A7: Comparing the evolution of detrended TFP and utilization-adjusted TFP, 1980:Q1 to 2015:Q1.

The figure conveys the same message: starting in 2007:Q3, both series exhibit a downward trend, with different high frequency movements. But it also reveals an important difference: while the deviations from trend of the measure of TFP we use in the main paper had not been previously seen in the sample, this is not the case for the adjusted measure of TFP. Indeed, during the early nineties, the deviations from trend of the adjusted series are much larger than the ones observed since the Great Recession. 


\section{References}

Bassetto, M., M. Cagetti, And M. D. Nardi (2015): "Credit Crunches and Credit Allocation in a Model of Entrepreneurship," Review of Economic Dynamics, $18,53-76$.

Buera, F., R. Fattal-Jaef, and Y. Shin (2015): "Anatomy of a Credit Crunch: From Capital to Labor Markets," Review of Economic Dynamics, 18, 101-117.

Calvo, G. A. (1983): "Staggered Prices in a Utility-Maximizing Framework," Journal of Monetary Economics, 12, 383-398.

Cociuba, S. E., E. C. Prescott, and A. Ueberfeldt (2012): "U.S. Hours and Productivity Behavior Using CPS Hours Worked Data: 1947-III to 2011-IV," Manuscript, University of Western Ontario.

Correia, I., E. Farhi, J. P. Nicolini, and P. Teles (2013): "Unconventional Fiscal Policy at the Zero Bound," American Economic Review, 103, 1172-1211.

Fernald, J. G. (2012): "A Quarterly, Utilization-Adjusted Series on Total Factor Productivity," Working Paper Series 2012-19, Federal Reserve Bank of San Francisco. 